\title{
Research on the integration of scientific and technological innovation in the Beijing-Tianjin-Hebei region
}

HengTian

Tianjin University of Finance and Economics, Tianjin, 300222, China

Keywords: Scientific and technological innovation platform, Integrated development, The Beijing-Tianjin-Hebei region.

\begin{abstract}
The integrated development of Beijing-Tianjin-Hebei region has become a major national strategy in 2014, the integration of scientific and technological innovation, significantly, is the core of regional coordinated development. However, the distribution of scientific and technological resources is uneven with lacking of an effective platform and cooperation mechanism, currently, leading to the inefficient collaboration of science and technology in the region. This paper puts forward the construction of scientific and technological innovation platform, with the specific responsibilities and leading direction of the participating departments, so as to provide feasible suggestions for the integrated development of Beijing-Tianjin-Hebei region.
\end{abstract}

\section{Introduction}

The Collaborative Development of Beijing, Tianjin and Hebei Province has proposed in 2008,and became the national strategical objective in 2014,indicating the transportation as well as ecological environmental protection industry are on the top list of the Beijing-Tianjin-Hebei coordinated development plan. Undoubtedly, the Beijing-Tianjin-Hebei urban agglomeration of collaborative innovation of science and technology is playing an extremely significant role in promoting the coordinated development of industry, industrial upgrading, industrial docking, industrial transfer and upgrading of industrial structure, which also is an important theoretical and realistic basis for the areas mentioned. Clearly, the innovation of science and technology collaborative development of Beijing Tianjin Hebei is more than irreplaceable to scientific research together with the upgrading and transformation of industrial. Rather, it has a significant impact on regional social change, related to the fundamental power of Beijing Tianjin Hebei regional integration and regional sustainable development. The collaborative innovation of science and technology is the core_ of course the main support to the Beijing-Tianjin-Hebei urban agglomeration. Compared with other regions, the Beijing-Tianjin-Hebei region in the dominant position of the superior scientific and technological research, for example, this are has the perfect technology system__ _ including the scientific and technological human resources and high-level university and research institutes, which in the leading ranks of the whole country. However, there is a great disparity, as many scholars found, in the level of economic development, technological research and innovation ability. Moreover, the human resources of science and technology are intensive but unevenly distributed, and the contact between the three areas is not closely.

This requires us, accordingly, to improve the management system of science and technology as soon as possible and establish a close cooperative relationship between Beijing, Tianjin and Hebei province, so as to play the great potential of this area and turn into a a new growth pole of the national economy. Therefore, how to effectively promote the Beijing-Tianjin-Hebei urban agglomeration of collaborative innovation of science and technology is an urgent problem to be solved. 


\section{Technological innovation platform}

\section{Scientific and technological innovation system in Beijing-Tianjin-Hebei region}

The function of the government, universities and enterprises of the scientific and technological innovation system is not clear enough in Beijing-Tianjin-Hebei region, this phenomenon causes more than difficulties in the scientific and technological innovation process. Rather, the technology researched, to a certain extent, is not targeted and forward-looking. The breadth and depth of cooperation between the three areas of the government, universities and enterprises is plain. The mode and research area of innovation are still in the imitation stage. As a result of the administrative space constraints, the technological ability of innovation in Beijing-Tianjin-Hebei region is weaken seriously. Restricted by the government, the technological ability of enterprise has been squeezed o long time, which leads to the minor space to develop for enterprises and civil organizations. Accordingly, the obstruct_- the technological ability of enterprise has severely circumscribed by government—_ should be solved by government instruments, itself. The government effected by the central planning in the long term ,in a manner, result in the inefficient technological innovation process of the three areas. Unrealizing the significance of the market economy, central planning has a passive impact on the government regulations, which brought about the lower level of reform and opening compared with south of China. Lacking of the perspicacity to the market operation mechanism, the north of China never break the rigid administrative system compered with Yangtze River Delta and Pearl River Delta. Moreover, it lacks of overall investment in scientific and technological innovation, particularly, mainly depends on the injection from the government. Inducing voluminous government capital, the scientific research institutions administrated by local government possesses a majority of outstanding science talents and abundant social resources, which causes a great proportion of state owned economy in the market and inhibitory effect as well as slow development of the private enterprise. Besides, with the noncompetitive and little vigorous market, the Beijing-Tianjin-Hebei technological innovation market can not form a long-term sustainable competition spiral mechanism. Although the scientific research institutions administrated by local governments could utilize substantial contribution, the technique and product driven by excessive pursuit of interests are inefficient and not targeted. Because the local government only concerned about their own development to develop planning for technological innovation, the Beijing-Tianjin-Hebei region does not form a practical sharing mechanism, which lead to the analogous research findings and invalid input of capital, human resources and social resources. Private enterprises, definitely, have more motivations to create new techniques and products meet the customer needs with valid and efficient operates. However, Some of them do not have enough money and ability to research new techniques with uncertainty, and they expect to use the existing scientific and technological achievements in low price.

\section{Capital investment and output in Beijing-Tianjin-Hebei region}

The Beijing-Tianjin-Hebei region is suppose to work on theoretical and practical innovation, considering the disadvantage of innovative ability of independent products and high value-added independent intellectual property in the market. In addition, the manufacturing process that cannot participate in the core of the product_— technology research and development—shares heavily in the whole production chain of Beijing-Tianjin-Hebei region. If the enterprises do not strengthen the innovation of corresponding products, they will continue to be in the backward state with low margins. Judging from the current situation, Tianjin takes the priority in the research and development of new energy vehicles and the production of key components, but Tianjin does not have the best-known auto brand. It is estimated that the investment of new energy vehicles in Tianjin will reach 80 billion yuan at the end of the 13th five-year plan, what is important to Tianjin, hence,is develop its brands in the new energy development with taking advantage of the research development.

\section{Science and technology innovation system in Beijing-Tianjin-Hebei region}

Strengthen the valid cooperation of the government, universities and enterprises to work on the scientific and technological innovation is the urgent task to be done. The government should reduce the excessive control of the scientific and technological resource, break the administrative and 
ideological barriers of the central pan effect to balance the relationship of government and market, in order to form a science and technology innovation system mainly depends on market accompanied with the governmental interferes for assistant. To strive to build a scientific and technological innovation platform contained government, enterprises, production, learning and research, with a cross-regional integration of resources. The Beijing-Tianjin-Hebei region is suppose to develop new innovative pattern, such as order-based innovative model and collaborative programs, relying on the advantages of technology, resource and talents.

\section{The government}

Driving economic growth markedly, the government policy has a strong guiding effect on the flow of economic resources. The government could improve the environment of innovative development market through positive-headed policies_—strengthen the support of enterprises to innovate under the policy direction, maintain the appropriate government investment scale and reasonable investment structure, protect the enterprise Scientific and technological innovation space, stimulate the vitality of social capital and private organization, arouse innovative vigor of enterprise through financial subsidies, tax deduction and exemption and free loan. All in all, sharing the uppermost priority, the government policy has a positive effect on Innovation resource allocation and improving innovative efficiency.

\section{The university}

The university, to be sure, is the main part of theoretical and technological innovation In the Beijing-Tianjin-Hebei technological innovative system by virtue of its large amount of talents and the interdisciplinary research. Via the integration of technical resources and experts of the universities and scientific institutions in the three areas, the knowledge-based resources will be turned into technological innovation in a more valid and efficient way. As a matter of fact, colleges ought to clarify whether their achievements in scientific research are in accord with market demand, economic and social development as well as the coordinated development for the Beijing-Tianjin-Hebei region. In the horizontal aspect, the collaborative innovation will be realized by cooperative development of disciplines. In the vertical aspect, the depth of innovation will be improved by the cooperation between colleges and enterprises.

\section{The enterprises}

Conscientiously, the weakest part is the product innovation in Beijing-Tianjin-Hebei region as the enterprises is irreplaceable to the sci-tech Innovation System. The enterprises ought to improve product innovation capability via the balance of technology import and independent innovation, increase the $\mathrm{R} \& \mathrm{D}$ funds and personnel, accelerate the process from technique to new product .If the technology can not be used in production process, it can not realize its value. Enterprises, the momentous platform in the Beijing-Tianjin-Hebei regional scientific and technological innovation system, should closely integrate the new production and the commercial market.

\section{Improve the innovative ability of the platform}

It is irreplaceable to improve the depth of the innovative platform under the two directions__ online and offline, targeted at perfecting the scientific and technological innovation platform in Beijing-Tianjin-Hebei region.

Offline platform — the sharing mechanism of technology and resource facility

Via establishing the mechanism of researching and sharing the scientific and technological resources based on pooling-of-interest, the offline platform will integrate the innovative resources, for example, regional key laboratories to exert the function of resources sharing and mutual benefit. When a enterprise introduces the advanced equipment and technology, the whole offline platform could share both the cost and value to maximize the efficiency of use.

Science and technology intermediate — the new economic service_—is appeared after the close integration of economic development and the science and technology innovation. The Science and technology intermediate service industry functions to innovation subject containing government, colleges and enterprises, and various resources including talents and equipment through technical communication and promotion, information collection and arrangement and scientific statistical 
system. It is a catalytic agent and key connection to serve the scientific and technological innovation activities and improve the efficiency of innovation in the three areas.

Science and technology intermediate, at the same time, will become the new innovation subject in the three areas by undertaking the partial governments function. It will accelerate the mechanism of transformation from scientific and technological achievements to new products, so more economic benefits will be earned earlier.

\section{Online platform— — sharing of big data}

There are a large number of enterprises, universities and scientific research institutions, possessing comprehensive information resources. That poses difficulties to process information timely and effectively in the traditional way at the request of competitiveness and timeliness of the contemporary economic development. Accordingly, the cloud computing and big data technologies should be applied in the Beijing-Tianjin-Hebei technological innovative system to establish a database of regional collaborative innovation consisting of the various information of enterprises, colleges, research institutions and science and technology intermediates. The function, for example, declaration and approval of major projects, releasing information, searching for innovative resources and services and consultancy should be contained on the online platform, which incorporates resources, policy and achievements of science.

The online platform is a new mode that focuses on the collaborative development of the various subject to innovate as well as integrating the exiting resources. The launch of the online platform, the database of regional collaborative innovation, is the first step to realize the Beijing-Tianjin-Hebei technological innovative system in the arrived era of big data. Eventually, the regional science and technology service network guided by the market will be formed, which provides comprehensive innovation services.

\section{References}

[1] Adomavicius G, Bockstedt J C, Gupta A. Technology roles and paths of influence in an ecosystem model of technology evolution[J]. Information Technology \& Management, 2007,8(2):185-202.

[2] Roberts J,Gertner D, Charles D. University-industry collaboration: A cops approach to KTPs[J]. Journal of Knowledge Management, 2011,15(4):625-647.

[3] Cardeña R, Ashburner G R, Oropeza C. Bilateral collaboration and the emergence of innovation networks[J]. Management Science, 2007,53(7):1051-1067.

[4] Rothwell R. Successful industrial innovation: critical factors for the 1990s[J].R\&D Management, 1992, 22(3):221-240

[5] Gurley J G, Shaw E S.Money in A Theory of Finance[M].Washington DC:The Brookings Institution, 1960:13-18. 